\title{
Andrej Šgula
}

\section{Upanje in zaupanje v kontekstu pastoralne teologi- je v času globalnega nezaupanja}

\section{Hope and Trust in the Context of Pastoral Theology in a Time of Global Mistrust}

Povz̨etek: Pandemija covida-19 je v življenje Cerkve prinesla mnogo sprememb, ki se kažejo na različnih področjih pastoralnega delovanja. Govorimo o stvareh, ki jih je korona odnesla, na drugi stran pa o spremembah, ki se kažejo kot dobre. Ob vsem tem se v človeku naselijo tudi strah, negotovost, morda celo obup in nezaupanje. Ko govorimo o zaupanju oz. nezaupanju, ne moremo mimo dejstva, da Slovenci Cerkvi zaupajo zelo malo, prav tako pa zelo malo zaupajo duhovnikom (raziskava Valicona 2019). Človek v današnjem svetu dobi občutek, da Boga ne potrebujemo. Kljub situaciji pastorala išče izhod. Nekateri slovenski pastoralisti se navdihujejo ob primerih dobre prakse kanadskega duhovnika Jamesa Mallona, ki je s svojim izvirnim pristopom presegel temeljne paradigme obstoječe pastorale. Sam pravi, da so se njegove župnije spremenile, ko je v središče prizadevanja za evangelizacijo postavil tečaj Alfa. Pri tem njegove ,reforme' ne zadevajo samo struktur, ampak segajo tudi na duhovna področja. Primer dobre prakse v slovenskem prostoru vidimo denimo v Slovenj Gradcu, kjer so postavili nove temelje pastoralnega delovanja. In ti premiki dajejo upanje, da tudi Cerkev zapušča držo ,vzdrževalca' struktur in se usmerja k misijonu.

Ključne besede: pandemija, obup, zaupanje, nezaupanje, James Mallon, pastorala, Alfa

Abstract: The coronavirus has brought many changes in the life of the Church, which are reflected in various areas of pastoral activity. We are talking about the things that the ,corona' has taken away, and on the other hand, about the changes that are proving to be good. With all these changes, fear, insecurity, maybe even despair and mistrust merge in a person. When we talk about trust or distrust, we are surprised by the facts that indicate that Slovenes trust the Church very little and also trust priests very little (Valicon 2019 survey). In today's world, man gets the feeling that we do not need God. Despite the situation, pastoral care is looking for a way out. Some Slovenian pastoralists are inspired by the examples of good practice of the Canadian priest James Mallon, who, with his original approach, went beyond the basic paradigms of the existing pastoral care. 
He considers that his parishes changed when he put the Alpha course at the center of the evangelization effort. His ,reforms' do not only concern structures but also reach spiritual areas. We see an example of good practice in Slovenia in Slovenj Gradec, where new foundations for pastoral work have been laid. Moreover, these shifts are the hope that the Church, too, is abandoning the position of ,maintainer' of structures and moving in the direction of the mission.

Keywords: pandemic, despair, trust, distrust, James Mallon, pastoral, Alpha

\section{Uvod}

Praktična pastoralna teologija je vpeta v prostor in čas. Dogodki v družbi in v svetu vplivajo tudi na življenje, delo in poslanstvo na področju pastorale in pastoralne teologije. To se jasno kaže tako ob prerezu zgodovine kakor tudi ob bežnem pogledu v dogodke današnjega časa. Kot je za svet pomembno, da prizna Cerkev kot družbeno stvarnost in kot njen kvas, tako tudi Cerkvi ni neznano, koliko je prejela iz zgodovine in razvoja človeštva (CS, tč. 44,1). Zgolj ob celostnem pogledu lahko začutimo obup in nezaupanje. Pri tem ne smemo spregledati statusa, ki ga ima glede zaupanja Cerkev v družbi (raziskava Valicona 2019), vendar je hkrati treba upoštevati situacijo in razmere, v katerih živimo. Pandemija covida-19 je namreč zbegala tako kristjane kot nekristjane, verujoče in neverujoče. Mnogo tega, na kar smo se doslej zanašali, se je sesulo ali zamajalo - in to ne glede na naš svetovni nazor ali vero (Lennox 2020,19). Kako naj vse to sprejmemo in premagamo, kako naj obrnemo kazalnike od obupa in nezaupanja v smer upanja in zaupanja? Morda drzna, a smiselna pot je v obratu k občestvu. "Prilagoditi se mora izrednim razmeram današnjega človeka, njegovi zmožnosti dojemanja, krhkosti, saj le tako omogoči odrešenju, da zares deluje.« (Vodičar 2020, 101)

\section{Problem zaupanja v odnosu do Cerkve}

Pastoralna konstitucija o Cerkvi v sedanjem svetu govori tudi o neravnovesju v današnjem svetu. $V$ notranjem svetu osebe same pogosto nastopa neravnovesje med sodobnim praktičnim umovanjem in teoretičnim načinom mišljenja, ki mu ne uspeva, da bi celoto svojih spoznav obvladal in jih uredil v zadovoljive sinteze. Prav tako nastajajo neravnovesja zaradi napetosti med prizadevanjem za praktičen uspeh in zahtevami nravne vesti, mnogokrat pa tudi zaradi nasprotja med razmerami kolektivnega življenja in težnjami po osebnostnem mišljenju ali celo po kontemplaciji. Končno nastaja neravnovesje med razdrobljenostjo človeške dejavnosti in celostnim gledanjem na stvari (CS, tč. 8,2).

V Katekizmu Katoliške cerkve je beseda o skrivnosti Cerkve, ki pravi, da ima Cerkev svoje mesto v zgodovini, a jo hkrati presega. Samo ,z očmi vere' moremo v njeni vidni stvarnosti videti hkrati duhovno stvarnost, nositeljico božjega življenja (KKC, tč. 770). 
Odnos Cerkve do družbe je treba definirati po delih. Gre za različne poglede od tistih uradnih, statističnih, pa vse do tistih na ,terenu': med ljudmi, po župnijah (Kraner 2019). Leta 2019 je družba Valicon izvedla raziskavo z vprašanjem, komu Slovenci najbolj zaupajo. Kar se tiče zaupanja v institucije, Slovenci najbolj zaupamo malim slovenskim podjetjem, na tretjem mestu je policija, na četrtem vojska, na sedmem šolstvo, na osmem predsednik republike, na enajstem RTV Slovenija, na sedemnajstem sodišča, na devetnajstem mediji, na dvajsetem vlada in na enaindvajsetem mestu Cerkev. Za Cerkvijo so samo še stranke vladne koalicije, državni zbor - in na zadnjem mestu stranke opozicije.

Pri tem se človeku zastavi vprašanje, zakaj je Cerkev kot institucija zdrsnila tako ,globoko'. Kateri ,madeži' so povzročili tako situacijo?

Naslednje vprašanje $v$ raziskavi se je nanašalo na zaupanje v poklice. Tudi tukaj so bili odgovori presenetljivi. Na prvo mesto so anketiranci postavili gasilce, na drugo medicinske sestre, na tretje znanstvenike, na osmo učitelje, na enajsto univerzitetne profesorje, na šestnajsto tožilce. Šele na dvaindvajseto mesto so postavili duhovnike. Za duhovniki so še samo vladni ministri (23. mesto) in politiki na splošno (24. mesto). Trend rasti se je sicer v letih 2012-2019 rahlo dvignil. Duhovnikom zaupajo do 7 \% bolj in Cerkvi 9 \% (raziskava Valicona 2019). Toda še vedno sta zaupanje $v$ Cerkev in duhovnike na dnu lestvice.

Ob pogledu na temeljno poslanstvo Cerkve in rezultate raziskave Valicona 2019 se zastavlja mnogo vprašanj. Kaj povzroča tako stanje in položaj Cerkve? Človek lahko najprej pomisli na škandale v Cerkvi - finančni kolapsi, spolne zlorabe ipd. Branko Cestnik je naredil primerjavo s Španijo, kjer je stanje primerljivo z izsledki slovenske raziskave - na vrhu so prostovoljna združenja, policija, šolstvo. Na sredini sodstvo in novinarstvo. Na dnu lestvice pa sindikati, politika in Cerkev. Tako je španska situacija primerljiva z rezultati slovenske raziskave. Prav tako je dejstvo, da se tradicionalnim institucijam in tradicionalnim ponudnikom političnega in svetovnonazorskega smisla ne zaupa več. Raziskave so pokazale, da se najbolj zaupa onim, ki delajo brezplačno, takoj za njim so tisti, ki so za pomoč vedno pri roki. To pa verjetno pomeni, da hierarhična Cerkev v zavesti modernega človeka še vedno uteleša pojem velike tradicionalne institucije, ki ni priljubljena (Cestnik 2019).

Človek v današnjem svetu in času dobi občutek, kot da Boga ne potrebujemo več. Govorimo, da je Bog mrtev (Nietzsche) ali o Božjem mrku (Buber), govorimo o milenijcih (rojenih nekje v letih 1981-1999) kot o najbolj neverni generaciji v zgodovini Zahoda. In v tem kontekstu rezultate raziskav in mesto zaupanja v Cerkev in duhovnike lažje razumemo (Cestnik 2019).

V obdobju zadnjih deset, petnajst let opažamo, da se je v slovenskem prostoru odnos do Cerkve močno spremenil. Če izhajamo iz raziskave Slovensko javno mnenje $2011,{ }^{1}$ ugotovimo, da gre za najnižje zaupanje v Cerkev v času samostojne

Slovensko javno mnenje (SJM) 2010 je raziskava, ki je bila opravljena kot del Evropske družboslovne raziskave 2010 (ESS 2010). ESS je akademsko vodena mednarodna anketa, ki je bila do sedaj izvedena že $v$ več kot 30 državah. 
Slovenije - veliko ali precejšnje zaupanje v Cerkev izraža le 25 \% Slovencev. Eden od bistvenih dejavnikov, ki so na tako stanje (izrazito) vplivali, je gotovo finančni polom v Mariborski škofiji. Posamezni analitiki na osnovi raziskave ugotavljajo, da je zaupanje v Cerkev upadlo tudi med cerkveno vernimi oz. rednimi obiskovalci verskih obredov. Vsa ta dogajanja, ki so zaupanje v Cerkev načela, pa nimajo vpliva samo na sedanjo situacijo, ampak tudi na prihodnost.

Dejstvo je, da z nezaupanjem pada tudi statistika vernikov v naših občestvih, v naših župnijah. Po podatkih Statističnega urada RS je imela Slovenija 1. januarja 2020 2.095.861 prebivalcev Po podatkih slovenskih škofij pa je bilo v navedenem obdobju katoličanov 1.509.986 - kar je 72,11 \% delež (Letopis 2020).

\section{Današnji kontekst - pandemija koronavirusa}

Svet, v katerem živimo, je zaznamovan s pandemijo covida-19 in njenimi posledicami (Žigon 2020, 765-781). Ob tem se pojavlja vprašanje, če je med zaupanjem, nezaupanjem in obdobjem pandemije kakšna povezava. Dejstvo je, da je pandemija zaznamovala čas in življenje, pa tudi pastoralno življenje in delovanje. John C. Lennox piše, da je eden od glavnih učinkov epidemije vsesplošni občutek ranljivosti in nebogljenosti. Mnogi so se navadili na stabilen svet, v katerem je življenje razmeroma predvidljivo. Zdaj pa se zdi, da vse razpada - tega, na kar smo se vedno zanašali, ni več (Stegu 2020). Občutek imamo, kot da smo izpostavljeni silam, nad katerimi nimamo nadzora. Ljudje se bojijo za svoje zdravje, tako telesno kot duševno, za svoje sorodnike in prijatelje, za svoje ostarele, za preskrbo s hrano, za službe, ekonomsko varnost (Lennox 2020, 22).

Pandemija je ,napadla' občestvo. V Konstituciji o svetem bogoslužju beremo, da se je treba truditi, da se razcvete zavest župnijskega občestva zlasti v občestvenem obhajanju nedeljske maše ( $B$, tč. 42 ). Pandemija je onemogočila prav ta segment aktivnega verskega življenja. Zaprle so se cerkve, učilnice, župnijske pisarne. Na prvi pogled je župnijsko versko življenje ugasnilo - tam, kjer se je prej dogajalo pastoralno življenje, je nastal mrtev prostor. Nekateri verniki (ne pa vsi) so se zavedali, da je v novonastali situaciji praktično krščansko življenje v njihovih rokah. In čez noč se je rodila ,domača' Cerkev, malo občestvo. Dejstvo je, da je to ,zaprtje' vernike presejalo. Mnogi so ,dobili opravičilo', se umaknili in se nazaj v občestvo niso več vrnili. Zastavlja se vprašanje, ali gre tudi v teh primerih za nezaupanje v Cerkev kot institucijo.

Druga stvar, ki jo je pandemija ,napadla', pa je oznanjevanje, ki je eno izmed pomembnejših področij naše pastorale. Lahko bi rekli, da smo, ker oznanjamo. In tudi tukaj vidimo, da nas je pandemija zadela tam, kjer smo bili živi, kjer smo bili potrjeni. Mediji, ki smo jih še ,včeraj' odsvetovali, so čez noč postali naša rešitev (Spitzer 2016, 232) - ravno ta sredstva so postala edini kanal komunikacije in oznanjevanja (Šegula 2020, 21-23).

Pravzaprav je Cerkev reševala nastalo situacijo - in v tem reševanju je bilo veliko spontanega. Virtualno oznanjevanje se je pojavilo čez noč. V tem kontekstu 
lahko vidimo, da so se nekateri ,izgubili', ker sodobne medijske tehnologije niso vešči. Nekateri so o ,resničnosti‘ tega načina oznanjevanja dvomili - in tako sta se znova pritihotapila dvom in nezaupanje, ki sta občestva oklestila.

Vse to potrjujejo tudi številke, ki kažejo na številčni upad članov naših skupnosti.

\section{Vizija upanja na področju pastoralne teologije}

Vsak poskus nečesa novega, novega pastoralnega pristopa je neko upanje, da bomo kazalnike usmerili navzgor. O svoji negativni izkušnji piše Thomas Frings, ki se je službi župnika leta 2016 odpovedal in odšel v samostan - neke vrste odmik od aktivnega pastoralnega življenja in dogajanja. $V$ knjigi govori o nepravilnostih, o zgrešenostih, o neuspehu pastoralnega delovanja (Frings 2018). Zapustil je župnijo, zapustil je pastoralno delo - ker se je čutil neuspešnega in neučinkovitega. Po eni strani dobi človek občutek obupa, po drugi strani pa gre za iskanje novih poti.

Ob pregledu literature, ki opisuje pozitivne pastoralne izkušnje, ne moremo spregledati knjige, ki opisuje dobro prakso kanadskega duhovnika Jamesa Mallona. Po uspešni, temeljiti duhovni in pastoralni prenovi svoje župnije je izredno cenjen svetovalec pri prenavljanju župnijskih struktur in uresničevanju vizije nove evangelizacije. Napisal je tudi knjigo z naslovom Božja prenova, kjer z bralci deli številne razmisleke o možnostih za poživitev župnijskih skupnosti. Izhaja iz lastnih pastoralnih izkušenj. Našo pozornost usmerja na prehojeno pot, na vrednotenje sedanjega stanja, hkrati pa nam poskuša pokazati poti in možnosti za prihodnost. V svojem bistvu je Cerkev misijonska, zato James Mallon opominja, da morajo župnijska občestva postati zbor Jezusovih učencev, ki pogumno oznanja in deli radostno sporočilo evangelija z vso okolico (Družina 2021).

James Mallon je pri svojem pastoralnem delu razmišljal, kako priti do ljudi. Ne gre zgolj za tiste, ki so že v Cerkvi (ki so praktični kristjani), ampak predvsem za oddaljene. Zanj je bil tečaj Alfa pravo odkritje. Sam pravi, da nikoli ni doživel takih sadov, učenčevstva'. Po metodi tečaja Alfe je uspel nagovoriti ljudi različnih ozadij in stopenj vernosti. Sam pravi, da so se njegove župnije spremenile - da so doživele preporod, ko je tečaj Alfa postavil v središče prizadevanja za evangelizacijo. Tako je tečaj Alfa v njegovi župniji na široko odprl vrata nove evangelizacije. Istočasno je potekalo osem vzporednih tečajev z več kot tristo petdeset udeleženci, od katerih je bilo približno tretjina takih, ki v cerkev ne hodijo (Mallon 2021, 189).

Gre za reformo, ki je začela spreminjati podobo župnije, pa tudi pogled ljudi samih na župnijo kot občestvo, kot institucijo. Mallon ni želel le reforme struktur, ampak celostno transformacijo, ki vključuje tako strukture kot tudi duhovno sfero. $\mathrm{V}$ knjigi predstavlja analizo petih sistemov, ki vključujejo češčenje, evangelizacijo, učenčevstvo, občestvo in služenje. Avtor se naslanja na dokument iz Aparecide, ki ne postavlja le teologije za oblikovanje ,misijonarskih učencev', ampak ponuja tudi podroben opis procesa, ki ga za to potrebujemo. Prav ta dokument predlaga »pet te- 
meljnih vidikov v procesu oblikovanja misijonarskih učencev« (42). Prvi vidik je češčenje, ki dobi glavni poudarek v obhajanju evharistije. Češčenje lahko vključuje še molitvena srečanja in pa slavljenje v manjših skupinah. Drugi temeljni vidik je evangelizacija. Avtor pravi, da gre za oznanilo ali kerigmo, za veselo novico Božje ljubezni, ki se je razodela v Jezusu, in odrešenje, ki nam ga je podaril po križu in vstajenju - in to oznanilo je namenjeno tistim, ki Jezusa ne poznajo. Namen je pripeljati ljudi do odločitve, da Jezusu zaupajo, da mu sledijo in postanejo njegovi učenci. Tisti, ki na ta klic odgovorijo, jih evangelizacija pripelje do zakramenta krsta in sprave. Tako se evangelizacija ne ukvarja toliko z ljudmi ,znotraj' Cerkve, ampak je usmerjena na ljudi zunaj. Prav tako je pomemben tretji vidik - to je učenčevstvo. Gre za vseživljenjski proces rasti, dozorevanja in učenja. Učenčevstvo je povezano z evangelizacijo vključuje katehezo, prav tako pa rast v veri, spoznavanju, molitvi in odkrivanju od Boga danih darov. Četrti vidik je občestvo - po Novi zavezi je to koinonija ali skupno življenje. Občestvo ni samo množica ljudi, ki se ne pozna, temveč prav nasprotno - ljudje, ki se poznajo in ljubijo, se med sabo kličejo po imenu in podpirajo v klicu k svetosti. Vezivo takega občestva je ljubezen in odgovornost drug za drugega. Zadnji, peti poudarek je služenje bližnjim. Namen tega procesa je, da pripeljemo človeka do točke, ko začuti svojo poklicanost k služenju. James Mallon meni, da pravo merilo služenja v župniji ni število bralcev pri maši, ampak delež služb, ki odhajajo na ,eksistencialno obrobje', kot ga je imenoval Bergoglio (290-291).

Ta model kaže na uspešen, celostni pristop. Župnijska pastorala je lahko po teh korakih doživela preporod na vseh področjih, v vseh segmentih. Avtor James MalIon je gost mnogih pastoralnih srečanj, kjer te korake na področju župnijske pastorale predstavlja. Organizira tudi seminarje v Kanadi - v svoji župniji. Udeleženci prihajajo z vsega sveta.

\section{Upanje v slovenski pastorali}

Na stanje v naši slovenski pastorali je smiselno pogledati z več strani. En vidik je zaskrbljujoča raziskava, ki smo jo predstavili v tem članku, hkrati pa je treba videti dobre, pozitivne stvari po naših župnijah, na terenu. Vidimo, da stvari niso črno-bele. Če pogledamo slovensko statistiko v grobem, ugotovimo, da imamo v Sloveniji približno $10 \%$ praktičnih kristjanov. Okoli $70 \%$ slovenske populacije se opredeljuje za kristjane. Izziv za slovensko pastoralo vidimo v iskanju vstopnih mest. Kje in kako priti do teh kristjanov? V praksi vidimo več poskusov: krsti, pogrebi, poroke in neformalna srečanja. Vse to so ,vrata' do ljudi ,zunaj'.

Jamesu Mallonu je uspel preporod med drugim s tečajem Alfa. Ob pregledu stanja v Sloveniji vidimo, da so tudi pri nas - po zgledu modela Jamesa Mallona - narejeni prvi koraki. Rezultati so pozitivni, ponekod pa kar presenetljivi. $V$ kontekstu prenove pastoralnega delovanja lahko izpostavimo primer pastoralne zveze v Slovenj Gradcu, kjer so postavili življenje župnije (zveze župnij) na nove temelje. Ne gre le za strukturno reformo, temveč za celostno preobrazbo. Nosilci te preobrazbe so ,odkrili' model Jamesa Mallona, se ob njem navdušili in ga ,preve- 
dli‘ slovenskim razmeram ustrezno. Preporod se začenja z duhovnim življenjem - Jezusa Kristusa zavestno postavljajo v središče. Sledijo tudi vsem drugim vidikom: delo s praktičnimi kristjani (učenčevstvo), ustvarjanje občestev, pa vse do služenja (dati se na razpolago).

V času pandemije (popolnega zaprtja) se je oblikovala skupina duhovnikov (župniki, kaplani), ki so na dva tedna skupaj prebirali knjigo Jamesa Mallona Božja prenova in iskali navdihe za svoje konkretno pastoralno delovanje. Povabljeni so bili tudi drugi pastoralni sodelavci, ki so se srečevali v svoji skupini na Zoomu - da na področju pastoralnega delovanja poiščejo svoj prostor, svoje mesto.

In ti premiki so upanje, da tudi Cerkev v Sloveniji zapušča držo ,vzdrževalca' struktur in gre v smeri misijona. Pomenljiv je podnaslov knjige Jamesa Mallona, ki pravi: od vzdrževanja do misijona v župniji, ki bo v luči ozaveščanja vedno bolj omogočal tudi spremembo stvarnosti, v kateri živimo (Vodičar 2016, 378).

\section{Sklep}

V prvem delu članka smo predstavili raziskavo, ki nam kaže stopnjo zaupanja oz. nezaupanja družbe do Cerkve in duhovnikov. $V$ nadaljevanju pa smo želeli pokazati na primer dobre prakse. Gre za primer kanadskega duhovnika Jamesa Mallona, ki je uspel - kljub mnogim negativnim trendom - obrniti kazalnike v pozitivno smer. Njegov model pastoralnega delovanja je dokaz, da so premiki možni. Ob tem modelu so se navdušili tudi nekateri slovenski pastoralisti in prvi sadovi so že vidni (pastoralna zveza).

Vsekakor nam pri tem prizadevanju prihaja naproti tudi sinoda o sinodalnosti, ki so jo nekateri poimenovali ,sinoda od spodaj navzgor'. Glavni namen je, da bi sinodalnost, za katero se papež Frančišek zavzema že od začetka pontifikata in ki je tudi glavna tema sinode, vsi verniki tudi v praksi zaživeli še pred začetkom sinodalnih razprav na zborovanju oktobra 2023 - in sicer s posvetovanji in razločevanjem najprej na škofijski in celinski, šele zatem na vesoljni ravni. Kot poudarja sinodalni načrt poti, se bo celoten sinodalni proces verodostojno uresničil le, če bodo vanj vključene krajevne Cerkve (Pogačnik 2021).

$\checkmark$ vseh teh procesih ne gre ne za amerikanizacijo, niti ne za vatikanizacijo slovenske pastorale - temveč za iskanje načinov in oblik, ki so uresničljive v konkretnih pastoralnih situacijah (od spodaj). Temelj vsega pastoralnega prizadevanja je evangelij - gre torej za drugo ali pa celo že za tretjo evangelizacijo.

\section{Kratici}

CS - Koncilski odloki 2004 [Pastoralna konstitucija O Cerkvi v sedanjem svetu / Gaudium et spes (1965)].

B - Koncilski odloki 2004 [Konstitucija o svetem Bogoslužju / Sacrosanctum Concilium (1963)]. 


\section{Reference}

C., G. 2019. Raziskava Valicona: Slovenci med poklici najbolj zaupajo gasilcem, najmanj politikom in duhovnikom. MMC - RTV Slovenija, 12. 1. https://www.rtvslo.si/slovenija/raziskava-valicona-slovenci-med-poklici-najbolj-zaupajo-gasilcem-najmanj-politikom-in-duhovnikom/477045 (pridobljeno 17. 6. 2021).

Cestnik, Branko. 2019. Slovensko nezaupanje v Cerkev ni noben fenomen, podobni trendi so tudi na Zahodu. Portalplus, 13. 1. https://www. portalplus.si/3044/nezaupanje-v-verkev?desktop=1 (pridobljeno 17. junija 2021).

Frings, Thomas. 2018. Dovolj, amen, konec? Tako ne morem več biti župnik. Ljubljana: Salve.

Koncilski odloki. 2004. Ljubljana: Družina.

Kraner, David. 2019. Le rappresentazioni sociali della Chiesa Cattolica in Slovenia. Rim: LAS.

Lennox, John C. 2020. Kje je Bog v času koronavirusa? Ljubljana: Družina.

Letno poročilo Katoliške cerkve v Sloveniji. 2020. Ljubljana: Slovenska škofovska konferenca. https://katoliska-cerkev.si/media/datoteke/ Dokumenti\%20in\%20publikacije/LETNO\%20 POROCILO\%202020-SPLET.pdf (pridobljeno 17. 6. 2021).

Mallon, James. 2021. Božja prenova (Od vzdrževanja do misijona $v$ župniji). Ljubljana: Družina.
Pogačnik, Marjan. 2021. Sinoda od spodaj. Družina, 10. 10. https://www.druzina.si/clanek/sinoda-od-spodaj-navzgor-iz-arhiva (pridobljeno 13. 10. 2021).

Spitzer, Manfred. 2016. Digitalna demenca: Kako spravljamo sebe in svoje otroke ob pamet. Celovec: Mohorjeva družba.

Stegu, Tadej. 2020. Pandemija in oznanilo kerigme. Bogoslovni vestnik 80, št. 2:425-432.

Šegula, Andrej. 2020. Sodobni mediji in oznanjevanje v času pandemije. Cerkev danes 54, št. 3:29-31.

Vodičar, Janez. 2016. Pojem žrtve v vzgoji: iz skrb k odgovornosti. Bogoslovni vestnik 76, št. 2:373-383.

- - - 2020. Delo za kristjana v Cerkvi v somraku zlorab. V: Janez Vodičar, ur. V iskanju novega zaupanja v Cerkvi : pastorala in kateheza po razkritju spolnih in drugih zlorab, 94-106. Ljubljana: Teološka fakulteta.

Žigon, Tanja, in Boštjan Udovič. 2020. »Cerkev mora ostati ljudem blizu ne glede na čase«: prvi val koronavirusa (COVID-19) in versko življenje v Sloveniji - analiza primera. Bogoslovni vestnik 80 , št. 4:765-781. 